\title{
Experimental phase relations in the CaS-FeS system and their bearing on the evolution of Mercury
}

\author{
STEFAN PITSCH ${ }^{1}$, MAX W. SCHMIDT ${ }^{2}$, PAOLO A. SOSSI ${ }^{2}$ \\ AND CHRISTIAN LIEBSKE ${ }^{1}$ \\ ${ }^{1}$ Institute of Geochemistry and Petrology \\ ${ }^{2}$ ETH Zürich \\ Presenting Author: stefan.pitsch@erdw.ethz.ch
}

Sulfide liquids in terrestrial environments are near monosulfidic and contain predominantly $\mathrm{FeS}$ with varying amounts of other chalcophile elements (mostly $\mathrm{Ni}, \mathrm{Cu}$ and $\mathrm{Zn}$ ). At highly reducing conditions, as found in enstatite chondrites or on Mercury, oxygen fugacities $\left(f \mathrm{O}_{2}\right)$ are sufficiently low such that elements that are otherwise lithophile on Earth, $\mathrm{Ca}, \mathrm{Mn}$ and $\mathrm{Mg}$, form major components of sulfide phases and coexist with $\mathrm{FeS}$ (troilite)[1]. The importance of these phases lies in their utility as geothermometers, that is, as proxies for minimum temperatures experienced during enstatite chondrite formation [1] and their likely presence on very reduced planetary bodies, such as Mercury [2]. Here, we re-examine the troilite-oldhamite (CaS) binary at 950 to $1450^{\circ} \mathrm{C}$, owing to the limited amount of data on this system and the spread in its reported eutectic temperatures $[3,4]$.

Experiments were performed with stoichiometric mixtures of pure components in graphite capsules sealed in evacuated silica tubes at $\sim 10^{-5}$ bar, equilibrated at the desired temperature for $24 \mathrm{~h}$. Because Ca-sulfides are hygroscopic, quenched samples were prepared under dry conditions, and mineral compositions determined by energy-dispersive spectroscopy, while phase proportions were computed by image analysis. Because sulfide liquid is labile, its composition was estimated by mass balance. The eutectic point was determined by experimentally bracketing various bulk compositions.

The solubility of FeS in oldhamite was found to be higher than previously reported, reaching $7 \pm 2 \mathrm{~mol} \%$ at 1100 to $1350^{\circ} \mathrm{C}$. The composition of the eutectic was found to lie at $10 \pm 3 \mathrm{~mol} \% \mathrm{CaS}$, significantly poorer in $\mathrm{CaS}$ than previously suggested [4]. Its temperature lies between 1070 and $1100^{\circ} \mathrm{C}$. Our data are consistent with the exprimentally determined temperature by [4], not however with the composition.

Our experimental data suggest that $\mathrm{Ca}$ dissolves extensively in sulfides under graphite-saturated conditions at low pressures, which may have prevailed during crust formation on Mercury [5].

[1] Skinner \& Luce (1971) AmMin 56, 1269

[2] Nittler, Starr et al., (2011) Science 333, 1847

[3] Dilner, Kjellqvist \& Selleby (2016) J Phase Equilibria Diffus 37, 277

[4] Heumann (1942) Arch Eisenhuttenwes 15, 557

[5] Vander Kaaden \& McCubbin (2015) J. Geophys. Res. Planets 120, 195 